Progress in Chemical and Biochemical Research

\title{
Reduced graphene oxide based on simultaneous detection of neurotransmitters
}

\author{
G. Vinodhkumara, R. Ramyab, M. Vimalanc, I. Vetha Potheherd, A. Cyrac Peter ${ }^{*}$
}

a Department of Physics, Raja Doraisingam Govt. Arts College, Sivaganga, India.

$b$ Department of Bioelectronics and Biosensors, Alagappa University, Karaikudi, India.

c Department of Physics, Thirumalai Engineering College, Kilambi, Kancheepuram, India.

$d$ Department of Physics, Bharathidasan Institute of Technology (BIT) Campus, Anna University, Thiruchirappalli, India.

H I G H L I G H T S

- A simple and convenient method for synthesis of GO was reported and converted into rGO via strong reducing reagent.

- Electrochemical sensing of Dopamine and Uric Acid was investigated by CV, EIS and SWV.

- The modified electrode exhibits good reproducibility, selectivity, sensitivity and stability.

\begin{tabular}{l}
\hline A R T I C L E I N F O \\
\hline Article history: \\
Received: 2018-11-23 \\
Revised: 2018-12-07 \\
Accepted: 2018-12-25 \\
Available online: 2019-01-06 \\
Manuscript ID: PCBR-1811-1006
\end{tabular}

Keywords:

Graphene oxide (GO), Hummer's method, Cyclic Voltammetry, Electrochemical Sensor, Dopamine, Uric Acid.

\section{G R A PHICAL ABSTRACT}

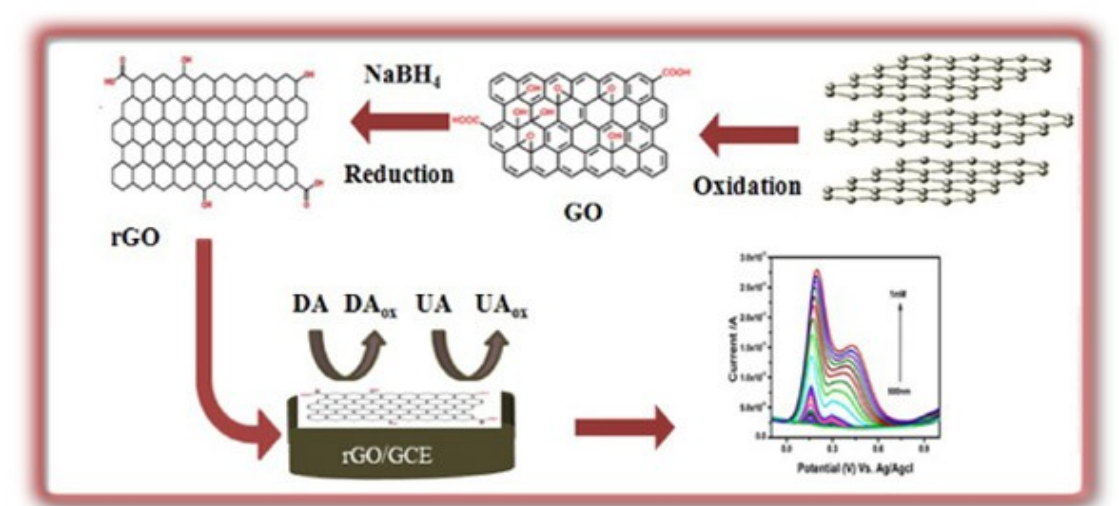

\section{A B S T R A C T}

Reduced graphene oxide (rGO) is synthesized using strong oxidizing agents with the help of chemical reduction method. Structural and physiochemical properties of the prepared sample are studied by ultraviolet-visible spectroscopy (UV-Vis), Fourier transform infrared spectroscopy (FTIR), X-ray powder diffraction (XRD) and scanning electron microscopy (SEM). UV-Vis spectra of GO exhibit maximum absorption peak attributable to restoration of $\mathrm{sp}^{2}$ carbon. Electrochemical study performed for bare and rGO modified glassy carbon electrode. Electrochemical sensing of Dopamine (DA) and Uric Acid (UA) was examined by cyclic voltammetry (CV), electrochemical impedance spectroscopy (EIS) and square wave voltammetry (SWV) were conducted in phosphate buffer solution (PBS) at $\mathrm{pH}=7.0$ done for both simultaneous and individual determination of DA and UA in the range of 500nM $1 \mathrm{mM}$ exhibit a wide linear range of detection and having low limit of detection (LOD) of $0.67 \mu \mathrm{M}$ for $\mathrm{DA}$, and $0.69 \mu \mathrm{M}$ for UA estimated for simultaneous determination and in individual determination it was found to be $0.51 \mu \mathrm{M}$ and $0.42 \mu \mathrm{M}$ for DA and UA respectively. Additionally, the modified electrode exhibits good reproducibility, selectivity, sensitivity and stability. The proposed sensor could be applied for the determination of DA and UA in real samples. 


\section{Introduction}

The emerging field of carbon based allotropes such as graphene, multiwall and singlewall nanotubes exhibits important role in field of electronics, optoelectronics, electrochemical and biomedical applications due to its unique structure and remarkable electronic, optical, thermal, mechanical and electrical properties[1-3]. One of the promising candidate among the allotropes of carbon is graphene is used for electrochemical sensing [4, 5], since every atom in a graphene sheet is a surface atom, molecular interaction and thus electron transport through graphene can be highly sensitive to adsorbed molecules [6]. Although various methods have been developed to prepare individual graphene sheets, such as chemical vapour deposition (CVD), micromechanical exfoliation of graphite and epitaxial growth on electrically insulating surfaces, chemical reduction of graphite oxide colloidal suspensions has been considered as an effective route to synthesize graphene sheets due to its simplicity, reliability, ability for large-scale production and cost effectiveness [7-9]. Graphite oxide consists of a layered structure of 'graphene oxide (GO)' sheets bearing a strongly oxygenated, highly hydrophilic layered material that can be readily exfoliated in water to yield stable dispersions consisting mostly of single layer, which are referred to as graphene oxide [10-14]. At present chemically converted graphene by the modified Hummers' method is the most widely used technique for preparing GO with excellent processability [15-17] which involves harsh oxidation of graphite to introduce abundant hydrophilic oxygenated functional groups.

Dopamine (DA) and Uric Acid (UA) plays vital roles in physiological functions of mammalian. Dopamine one of the most important catecholamine neurotransmitter widely distributed in cardiovascular, hormonal, renal and central nervous system [18]. Uric Acid is primary end product of metabolic breakdown of purine. Any abnormal change of both the biomolecules leads to cause for several diseases, such schizophrenia, Alzheimer's disease and parkison's disease in case of dopamine abnormalities[19]. On other hand, abnormal concentration levels of uric acid can cause gout, pneumonia, leukemia and hyperuricaemia[20-22]. Usually, dopamine coexists with uric acid in physiological samples which make major challenge in selectivity and sensitivity. Furthermore, their oxidation potentials are close to each other. To overcome these setbacks, we develop an rGO modified GC electrode for simultaneous electro-chemical detection of dopamine and uric acid. Modified electrode shows well defined peak separation and low limit of detection for DA and UA with good stability and reproducibility. Particularly, these factors suggest that the proposed sensor could be applied for determination of DA and UA in real sample analysis.

\section{Materials and methods}

\subsection{Graphite oxide preparation (GO)}

GO was synthesized from natural graphite powder by a modified Hummers method. Briefly, $2 \mathrm{~g}$ of natural graphite powder and $1 \mathrm{~g}$ of $\mathrm{NaNO}_{3}$ was added into a mixture of $70 \mathrm{ml}$ of $98 \%$ concentrated sulfuric acid (Conc. $\mathrm{H}_{2} \mathrm{SO}_{4}$ ). The mixture was stirred in an ice bath for 30 minutes at temperature below $20^{\circ} \mathrm{C}$ and then, $6 \mathrm{~g}$ of potassium permanganate was added to the suspension very slowly and stirred for $3 \mathrm{hrs}$ and maintained the temperature below $20^{\circ} \mathrm{C}$. After that, the suspended solution was transferred to water bath and stirred at $35^{\circ} \mathrm{C}$ for one hour. The mixture turns out dark green color in appearance. Then, $150 \mathrm{ml}$ of deionized (DI) water was added slowly and stirred for 40 minutes at $98^{\circ}$ $\mathrm{C}$ while the mixture turned dark brownish in color. After dilution with additional $240 \mathrm{ml}$ DI water and followed by $5 \mathrm{ml}$ of Hydrogen Peroxide $\left(\mathrm{H}_{2} \mathrm{O}_{2}, 30 \%\right.$ concentration)was added to the mixture to terminate the reaction and stirring for another 2 hours changing the color of the mixture from the dark brown to brilliant yellow. The 
resulting mixture was washed repeatedly with $10 \% \mathrm{HCl}$ and DI water to remove sulphate ions by centrifugation until $\mathrm{pH}$ attains 6 . Then the final product was dried in an oven for 24 hours.

\subsection{Reduced graphene oxide preparation (rGO)}

$400 \mathrm{mg}$ of graphite oxide powder was dispersed in $400 \mathrm{ml}$ of DI water via sonication vigorously for 1 hour to exfoliate the graphite oxide into graphene oxide. Then, $5 \%$ of $\mathrm{NaOH}$ was added to obtain the $\mathrm{pH}$ value at 9 . Thereafter, $4 \mathrm{~g}$ of $\mathrm{NaBH}_{4}$ was added to above dispersion and stirred for 1 hour. The resulting mixture was washed repeatedly with DI water by centrifugation, then dried at $50^{\circ} \mathrm{C}$ in an oven and the final product is collected and stored.

\subsubsection{Preparation and modification of electrodes}

Prior to modification, the bare Glassy carbon electrode GCE was polished carefully with $0.5 \mu \mathrm{m}$ alumina powder on polishing cloth and then rinsed ultrasonically in ethanol and water for 2 min, respectively. rGO was dispersed in deionized water $(1 \mathrm{mg} / \mathrm{mL})$ by using ultrasonicator. Then, $10 \mu \mathrm{L}$ of the prepared suspension was dropped onto the GCE surface by drop casting method and dried at room temperature for $1 \mathrm{hr}$ to obtain the rGO modified GCE.

\subsection{Characterization techniques}

Fourier transform infrared (FTIR) spectra of the samples were recorded on a spectrophotometer (Perkin ElmerSpectrum $\mathrm{RX} \mathrm{I)} \mathrm{using} \mathrm{KBr}$ as the mulling agent. Ultraviolet-Visible (UV-Vis) spectra of the samples were collected on a UV-Vis spectrophotometer (Perkin-Elmer Lambda 35), and X-ray diffraction analysis (XRD) of powders were carried out on XPERT-PROX-ray diffractometer with monochromatic $\mathrm{CuK \alpha}$, radiation $\left(\lambda=1.5406 \mathrm{~A}^{\circ}\right)$. Data were collected from $10^{\circ}$ to $80^{\circ}$ at a scan rate of $0.05^{\circ}$ per 10.16 seconds. The morphologies of the samples were observed under scanning electron microscope (Carl Zeiss EVO 18). Cyclic voltammetry, electrochemical impedance spectroscopy and square wave voltammetry measurements were performed with a $\mathrm{CHI}$ 6005D workstation (CH Instruments,USA). A conventional three-electrode system was employed comprising a glassy carbon electrode (GCE, $0.07 \mathrm{~cm}^{2}$ in diameter) coated with rGO as the working electrode, a platinum wire as the auxiliary electrode, and an $\mathrm{Ag} / \mathrm{AgCl}$ as the reference electrode.

\section{Results and discussion}

\subsection{Structural characterization}

\subsubsection{X-ray diffraction:}

XRD analysis is a non destructive technique to determine the phase formation, crystallinity of $\mathrm{rGO}$ sample as shown in the Fig. 1. Since XRD is not a perfect tool for identifying single-layer graphene, but it is very informative. The inset figure shows pristine graphite exhibits a basal reflection (002) peak at $2 \theta=25.5^{\circ}(\mathrm{d}$ spacing $=0.349 \mathrm{~nm}$ ) in the XRD pattern. After oxidation, graphite oxide (GO) shows a well-defined diffraction peak at $2 \theta=11^{\circ}$ with the interlayer spacing (d-spacing) corresponding to $0.8 \mathrm{~nm}$ which is very typical for GO [23]. This is an evidence to show that graphite is converted to graphene oxide. An increase in interlayer spacing of graphene oxide could be attributed to the intercalation of the oxygen functional groups like hydroxyl, epoxy and carbonyl as well as water molecules between graphene layers during the process of oxidation [24].

Also there is a very weak diffraction peak at $2 \theta=42.2^{\circ}$, which is believed due to the incomplete oxidation. After the reduction with $\mathrm{NaBH}_{4}$, the diffraction peak at $\left(11^{\circ}\right)$ of G0 was disappeared and a very weak and broad diffraction peak can be observed in the XRD pattern of rGO at $2 \theta=18^{\circ}-25^{\circ}$. This implies that the distance between the graphene of the oxygen and other functional 


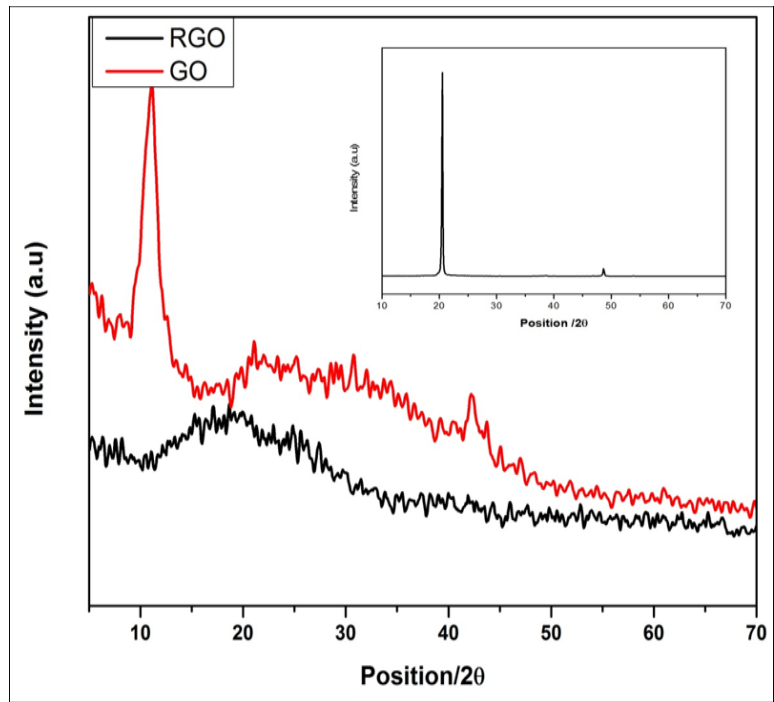

Fig. 1. X-Ray diffraction patterns Graphite (Inset), Graphite Oxide and rGO.

groups and restoration of carbon atoms in graphite network after the chemical reduction of $\mathrm{NaBH}_{4}$. Thus from the XRD results, it can be concluded that both epoxide and carboxylic functional groups were effectively reduced by sodium borohydride in line with the previous reports [25].

\subsection{Morphological characterization}

\subsubsection{SEM surface morphology}

Fig. 2 shows typical results of the studies of reduced graphene oxide. Fig 2(a) represents the view of the sample at lower magnification which stands for examining the area of $800 \times 800 \mu \mathrm{m}^{2}$ surface. Around the examined area, one can notice the presence of objects of sizes within $200 \mu \mathrm{m}$ to $300 \mu \mathrm{m}$. Those objects consist of tiny particles, as can be proved by SEM studies results gathered on one of the particles. The above results are shown in Fig. 2(b) $\left(25 \times 25 \mu \mathrm{m}^{2}\right.$ area, higher magnification). It is easy to notice that the examined particles consist of a number of smaller objects of $0.5 \mu \mathrm{m}$ to few micrometers in size. The problem was caused by the factor responsible for difficulties connected with getting higher magnification were high susceptibility of nanoparticles to aggregate into larger conglomerates. It should be pointed here that, except for nanoparticles

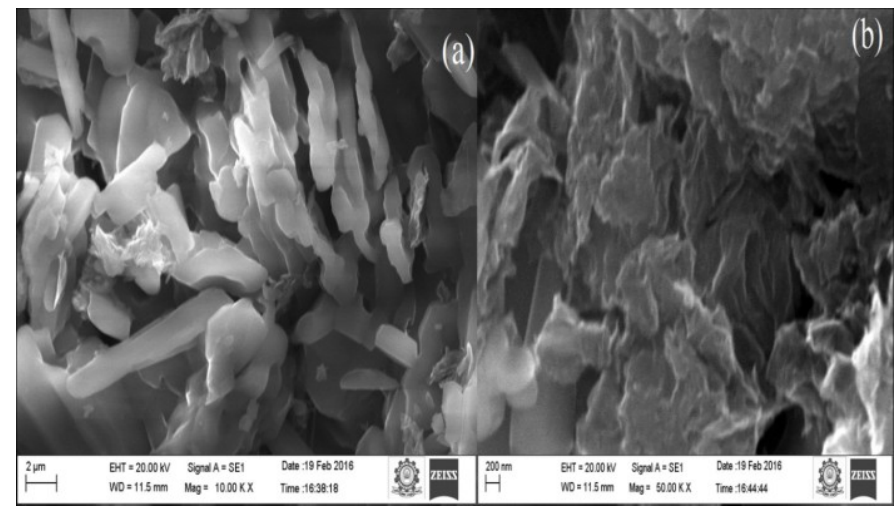

Fig. 2.SEM images of rGO (a) Lower magnification $\left(800 \times 800 \mu \mathrm{m}^{2}\right)$ (b) Higher magnification $\left(25 \times 25 \mu \mathrm{m}^{2}\right)$.

conglomerates, in GO powder there may appear stable grain of size ranging even to single micrometers.

\subsubsection{EDAX Analysis}

Fig. 3. shows a standard EDAX spectrum recorded to determine the elemental compositions of the sample. In the middle part of the presented spectrum one can clearly see three peaks located between $0.1 \mathrm{kV}$ and $1.2 \mathrm{kV}$. Those maxima are directly related to the GO characteristic lines $\mathrm{K}$ and $\mathrm{L}$. The maximum located on the left part of the spectrum at $0.2 \mathrm{kV}$ clearly comes from carbon. The hardly visible maximum located at $0.5 \mathrm{keV}$ is connected with the oxygen characteristic line. The carbon and oxygen spots in the examined samples confirm the presence of stabilizers composed of alkyl chains. The spectra obtained during EDAX studies were used for carrying out the quantitative analysis. For that purpose, SEM Quant software and the ZAF procedure were applied. Quantitative analyses GO reveals an atomic percentage of C (57.68\%), O (28.45\%) and $\mathrm{Na}(13.87 \%)$.

\subsection{FTIR Analysis}

Fig. 4 shows the FTIR spectrum of the reduced graphene oxide recorded in the range of $4000-400 \mathrm{~cm}^{-1}$. The band appeared at $3321 \mathrm{~cm}^{-1}$ corresponds to $\mathrm{O}-\mathrm{H}$ stretching vibrations. The peak $2916 \mathrm{~cm}^{-1}$ corresponds to alkanes $\mathrm{C}-\mathrm{H}$ stretching vibration. The peak $2141 \mathrm{~cm}^{-1}$ corresponds to alkynes $\mathrm{C}-\mathrm{C}$ stretching vibration. 


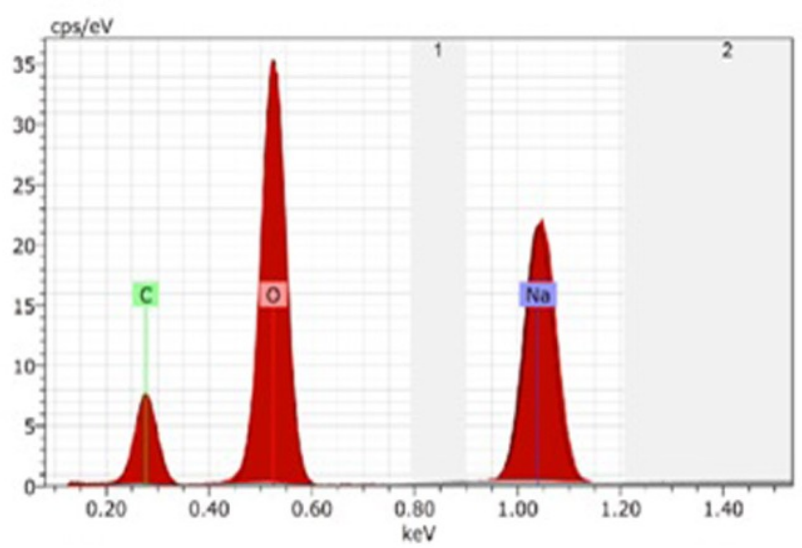

Fig. 3. EDAX image of rGO.

The peak $1695 \mathrm{~cm}^{-1}$ corresponds to $\mathrm{C}=0$ stretching and it confirms the presence of alkenes groups. The peak around $1560 \mathrm{~cm}^{-1}$ belongs to out of plane $\mathrm{C}=\mathrm{C}$ stretching vibration showed the presence of aromatic group. The peak of $1388 \mathrm{~cm}^{-1}$ corresponds to $\mathrm{C}-\mathrm{OH}$ stretching vibration. The peak of $1215 \mathrm{~cm}^{-1}$ corresponds to $\mathrm{C}-\mathrm{O}$ stretching vibrations. The peak of $832 \mathrm{~cm}^{-1}$ corresponds to $\mathrm{C}-\mathrm{O}-\mathrm{C}$ stretching vibration. The peak of $533 \mathrm{~cm}^{-1}$ corresponds to $\mathrm{NH}_{3}$ torsional oscillation. The intensities of the band associated with oxygen functional groups strongly decreased after reduction of $\mathrm{GO}$ by $\mathrm{NaBH}_{4}$. Particularly, the peaks at 1695,1560 , and $1215 \mathrm{~cm}^{-1}$ of GO were significantly reduced in intensity, indicating that the $\mathrm{C}=0$ stretching, $\mathrm{C}=\mathrm{C}$ aromatic, $\mathrm{C}-\mathrm{O}$ stretching and $\mathrm{C}-\mathrm{O}$ based functional groups had been removed by sodium borohydride. Hence, $\mathrm{NaBH}_{4}$ is found to be more effective in reducing oxygen functional groups.

\subsection{UV-Vis Analysis}

The reduction of GO into graphene is characterized by UV-Vis spectroscopy studies as shown in Fig. 5. The UV-vis spectrum of rGO shows an absorption peak at $270 \mathrm{~nm}$ which indicates the presence of few layer graphene. For few layer graphene, the absorption peak is expected to be from $230 \mathrm{~nm}$ to $270 \mathrm{~nm}$ during reduction and also suggesting that GO is reduced.

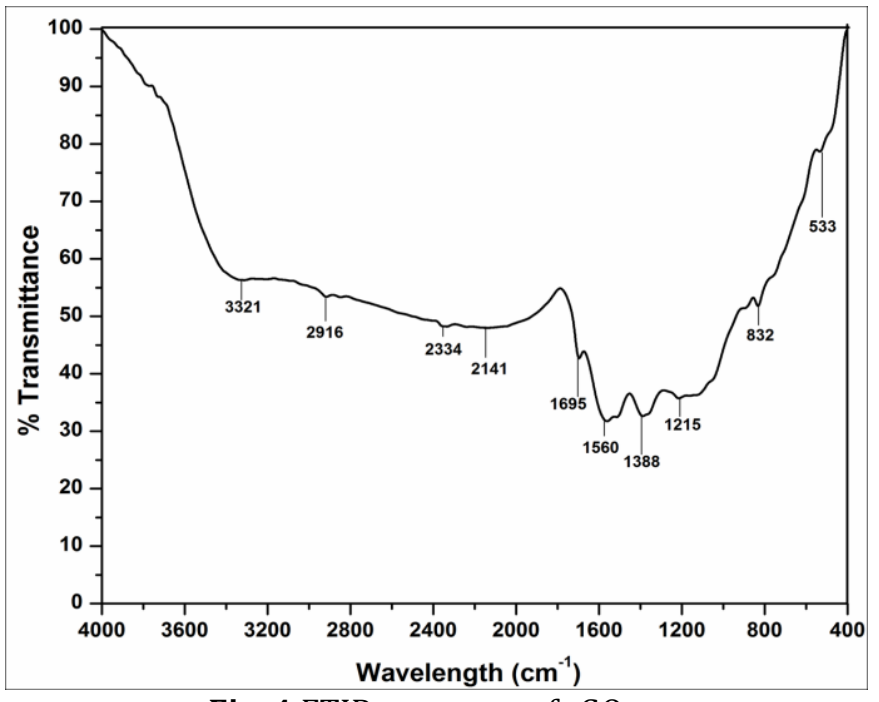

Fig. 4.FTIR spectrum of rGO.

The electronic conjugation within graphene sheets is restored upon $\mathrm{NaBH}_{4}$ reduction, reflecting increased $\pi$ electron concentration due to removal of $\mathrm{sp}^{3}$ carbon atoms and structural ordering, which is consistent with the restoration of $\mathrm{sp}^{2}$ carbon network and possible rearrangement of atoms. In addition, UV-Vis spectra analysis shows a shoulder at $370 \mathrm{~nm}$ in $\mathrm{rGO}$, which suggests an absorption peak may be due to $\mathrm{Na}[26,27]$ and an $n-\pi^{*}$ transition at $350 \mathrm{~nm}$ of $-\mathrm{C}=0$ bonds [28, 29].

\subsection{Cyclic Voltammetry Analysis}

\subsubsection{Electrochemical properties of rGO sample}

Fig. 6 shows CV behavior of bare and rGO modified GCE in presence of $1 \mathrm{mM}\left[\mathrm{Fe}(\mathrm{CN})_{6}\right]^{3-/ 4-}$ in $1.0 \mathrm{M} \mathrm{KCl}$ at a scan rate of $50 \mathrm{mVs}^{-1}$. CV values for bare and modified rGO are given in table1. Herein, we have noticed a pair of well-defined redox peak $\Delta \mathrm{Ep}$ values of $73 \mathrm{mV}$.

Table1. CV current and potential value for Bare and modified rGO.

\begin{tabular}{lllll}
\hline S.no & $\begin{array}{l}\text { Anodic } \\
\text { potential }\end{array}$ & $\begin{array}{l}\text { Cathodic } \\
\text { potential }\end{array}$ & $\begin{array}{l}\text { Anodic } \\
\text { current }\end{array}$ & $\begin{array}{l}\text { Cathodic } \\
\text { current }\end{array}$ \\
\hline Bare & 0.260 & 0.187 & $2.04 \times 10^{-5}$ & $-2.05 \times 10^{-5}$ \\
rGO & 0.281 & 0.117 & $2.01 \times 10^{-5}$ & $-1.88 \times 10^{-5}$ \\
\hline
\end{tabular}




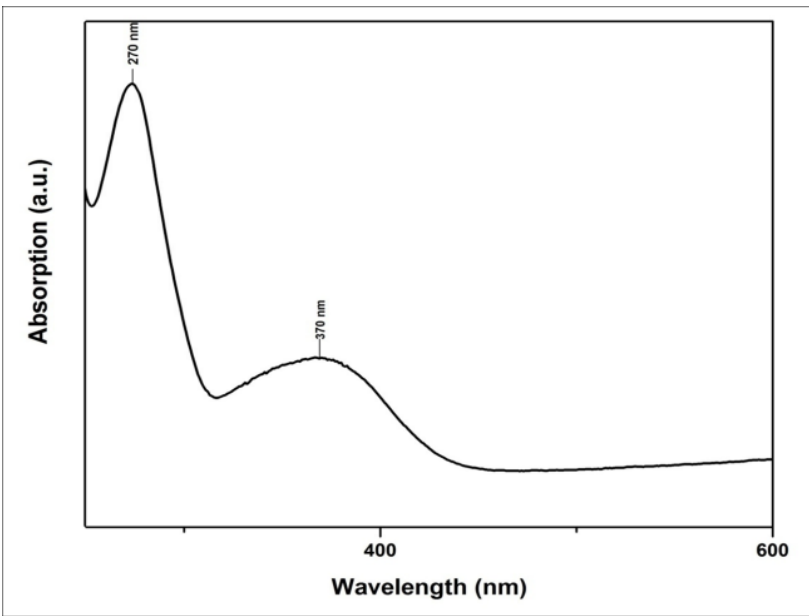

Fig. 5. UV Vis spectrum of rGO

Deposition of the rGO onto the electrode surface resulted in an irreversible behavior towards $\left[\mathrm{Fe}(\mathrm{CN})_{6}\right]^{3-/ 4-}$ voltammetry $(\Delta \mathrm{Ep}: 164 \mathrm{mV})$ as a result of hindrance of electron transfer. Interestingly, the rGO sample redox peaks are increased, due to lattice structures as evidenced by the generation of easily reducible oxygen species which resulted in a better electro catalytic performance.

Notably, the cathodic peak currents showed a significant increase due to enrichment of electron transfer. Electrochemical impedance spectroscopy provides very useful information about the electrochemical process. The behavior of the modified GC electrode is measured by impedance in the frequency region from $100 \mathrm{kHz}$ to 1 $\mathrm{Hz}$ and the DC potential $250 \mathrm{mV}$ and $\mathrm{AC}$ potential $5 \mathrm{mV}$ in the presence of $(1 \mathrm{mM})\left[\mathrm{Fe}(\mathrm{CN})_{6}\right]^{3-/ 4-}$ in $0.1 \mathrm{M}$ $\mathrm{KCl}$. The electron transfer capability of different modified electrodes was investigated by electrochemical impedance analysis and the corresponding results are shown in Fig. 7. The charge transfer resistance (Rct) values were obtained by the Randels equivalent circuit model $[\operatorname{Rs}(\mathrm{QCPE}(\operatorname{Rct}(\mathrm{W}))]$ using Zsimpwin software, where Rs is the solution resistance, Rct is the charge transfer resistance, $\mathrm{W}$ is the Warburg impedance and QCPE is the constant phase element. The Rct at different stages altered with the successive modification of rGO in $\left[\mathrm{Fe}(\mathrm{CN})_{6}\right]^{3-/ 4-}$ as the redox probe.

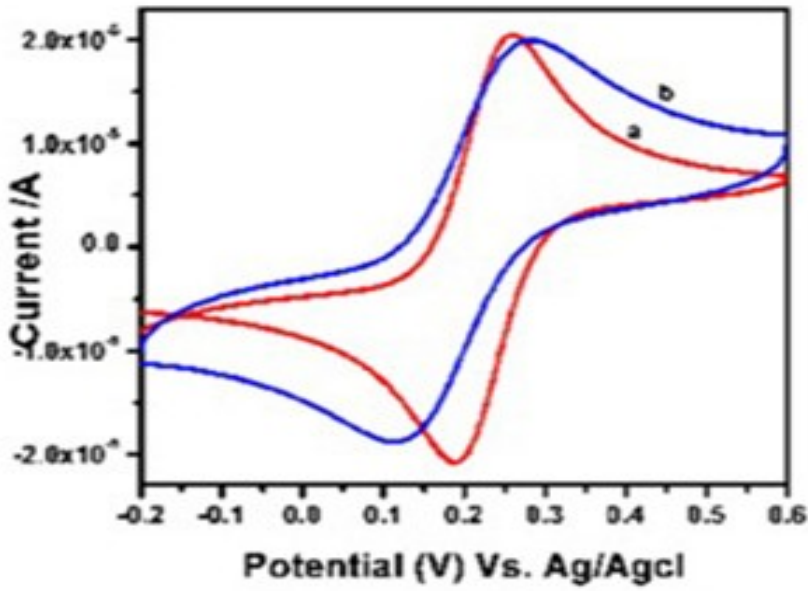

Fig. 6. Cyclic voltammetry analysis (a) bare GC, (b) rGO modified GCE.

The Rct values of bare and rGO samples were 96.1 and $3919 \Omega \mathrm{Cm}^{-2}$ respectively. It shows the electron transfer resistance of the electrode decreased after the modification.

\subsubsection{Effect of varying scan rate}

Fig. 8 shows the effect of varying scan rates on the cyclic voltammograms performed in $1 \mathrm{mM}\left[\mathrm{Fe}(\mathrm{CN})_{6}\right]^{3-/ 4-}$ precursor using GO modified electrode in $1.0 \mathrm{M} \mathrm{KCl}$ solution was studied over scan rate range of $10 \mathrm{mV}$ to $100 \mathrm{mV} / \mathrm{s}$. Oxidation currents were observed to increase with scan rate due to heterogeneous kinetics.

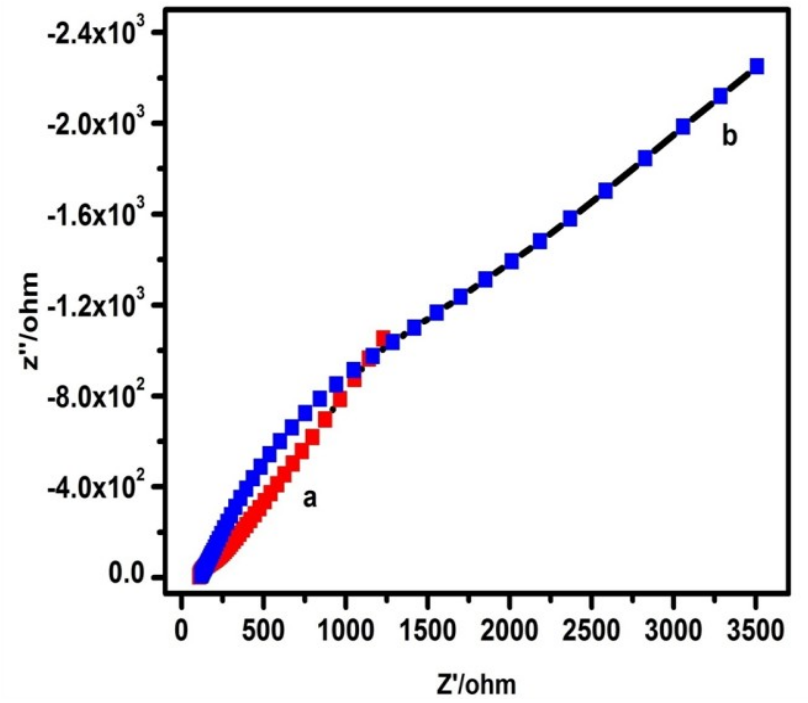

Fig. 7. EIS behavior, (a) bare GC, (b) rGO modified GCE. 


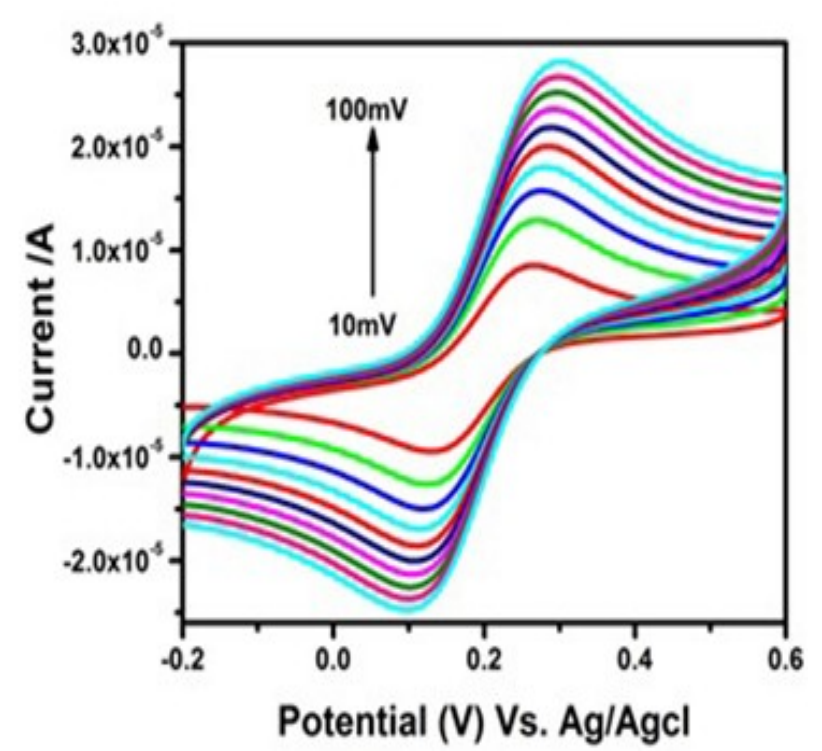

Fig. 8. Cyclic voltammetry of rGO modified GCE at different scan rates.

Furthermore, the oxidation and reduction peak currents increased linearly with the square root of scan rate, while the cathodic peak potentials varied linearly with the logarithm of scan rate.

A good linearity was obtained while plotting the current against the scan rate shown in Fig. 9 indicate that the oxidation of $\left[\mathrm{Fe}(\mathrm{CN})_{6}\right]^{3-/ 4-}$ was a diffusion controlled process.

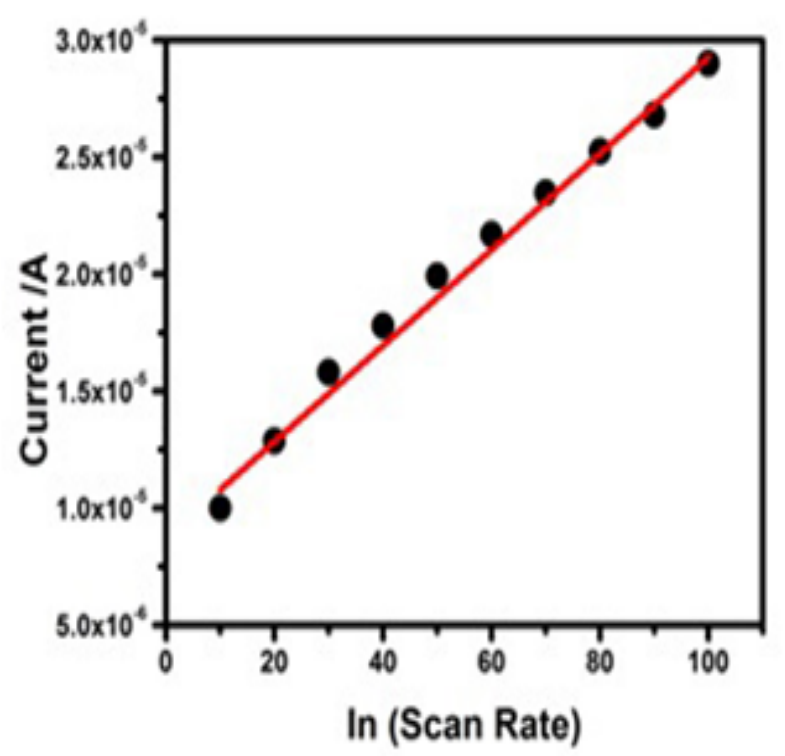

Fig. 9.Linear fit plot of current against scan rate.

\subsubsection{Sensitivity of the modified electrode using SWV}

The sensitivity of the rGO a nanostructure towards the detection of DA \& UA was calculated by performing the square wave voltammetry (SWV) at various concentrations. SWV is performed in the potential range $0.1 \mathrm{~V}$ to $0.8 \mathrm{~V}$ with $0.1 \mathrm{M}$ phosphate buffer solution with $\mathrm{pH}$ 7.0. The DA and UA were injected from $500 \mathrm{nM}$ to $1 \mathrm{mM}$ into the PBS. In each step of addition of DA \& UA, the corresponding current value is noted. It is evident from Fig. 10 (a) and (b), with an increase in the DA \& UA concentration. We have witnessed an increase in the peak current.

3.5.4 Individual and simultaneous determination of dopamine (DA) \& Uric acid (UA)

A novel modified reduced graphene oxide electrode for the simultaneous determination of dopamine and uric acid has been developed. The modified rGO/GCE film was studied by square wave voltammetry. The effects of various concentration and pulse amplitude were examined to optimize the conditions of square wave voltammetry. The rGO/GCE was well accomplished and determined in the concentration range of $500 \mathrm{nM}-1 \mathrm{mM}$ for Dopamine and Uric Acid. The SWV oxidation peak potential of DA and UA (Fig. 11) were at $0.17 \mathrm{~V}$ and $0.29 \mathrm{~V}$ respectively and well defined peak separation of $0.12 \mathrm{~V}$ between DA and UA which implies modified electrode successfully prevent the overlap of oxidation potential of two biomolecules. The oxidation peak current of these analytes increased linearly with increased concentration. The linear range for simultaneous determination is $0.5 \mathrm{x}$ $10^{-6}$ to $1 \times 10^{-3} \mathrm{M}$ for both DA and UA with limit of detection $0.67 \mu \mathrm{M}$ and $0.69 \mu \mathrm{M}$ respectively. The present results are compared to those in literature (Table 2). 

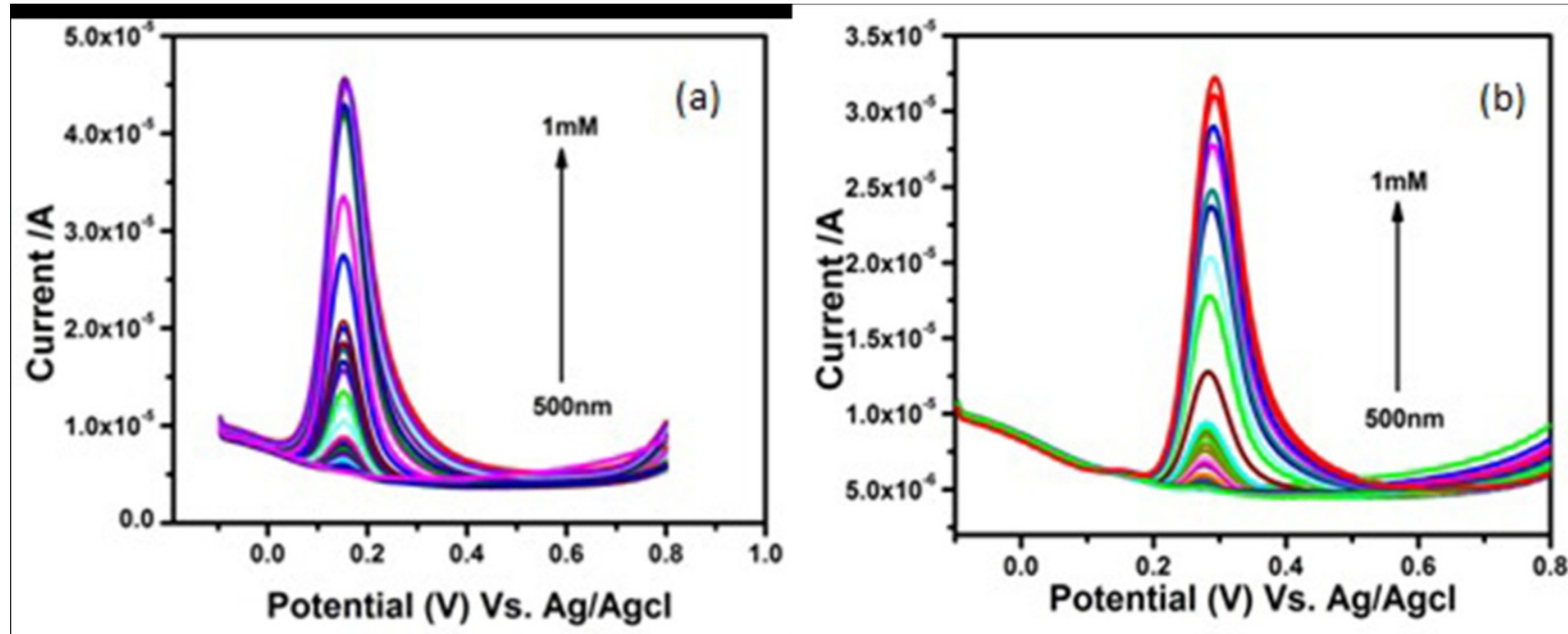

Fig. 10.SWVs Obtained for various concentrations in the range of $500 \mathrm{nM}$ to $1 \mathrm{mM}$ at rGO modified GCE in $0.1 \mathrm{PBS}$ pH 7.0 (a) Dopamine (b) Uric Acid.

The results shows the rGO modified electrodes has better selectivity and sensitivity compared with previous report. Main advantages as for individual and simultaneous detection there is no decreases or increases linear ranges it confirmed the modified electrode shows reasonable biomarker as Parkinson diseases [30]. Thus, rGO with unique structural properties are promising candidate for biosensor and bioelectronics.

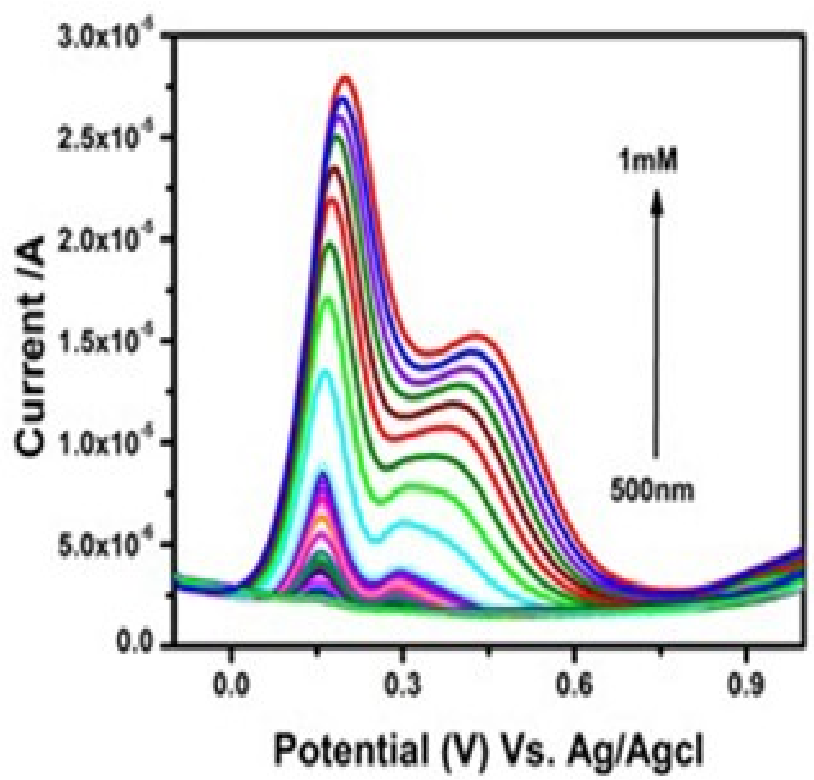

Fig. 11. SWVs obtained for simultaneous of dopamine and Uric acid 500nM to $1 \mathrm{mM}$ at rGO modified GCE in 0.1M PBS pH 7.0.

\section{Conclusion}

We have reported a simple and convenient method for synthesis of GO and converted into $\mathrm{rGO}$ via strong reducing reagent. The XRD results shows GO has $2 \theta$ at $11^{\circ}$ with inter layer spacing equal to $0.8 \mathrm{~nm}$ and $\mathrm{rGO}$ shows a broad diffraction peak which implies the restoration $\mathrm{sp}^{2}$ carbon network. The FT-IR analysis displays decreased intensity of characteristic peaks corresponds to oxygen functional groups which imply a successful reduction and formation of rGO phase. UV-vis spectrum of rGO exhibits maximum absorption peak at $\sim 270 \mathrm{~nm}$. SEM images demonstrate ultrathin and homogeneous graphene films.

Table 2. Comparison of different chemically modified electrodes for the determination of DA and UA with $\mathrm{rGO} / \mathrm{GCE}$.

\begin{tabular}{|c|c|c|c|c|c|}
\hline \multirow[t]{2}{*}{ Electrode } & \multicolumn{2}{|c|}{$\begin{array}{l}\text { Linear range } \\
\qquad(\mu \mathrm{M})\end{array}$} & \multicolumn{2}{|c|}{$\begin{array}{r}\text { Detection } \\
\text { limit }(\mu \mathrm{M})\end{array}$} & \multirow[t]{2}{*}{ Ref } \\
\hline & DA & UA & DA & UA & \\
\hline Caffeic acid/GCE & - & $5-300$ & - & 60 & [31] \\
\hline $\begin{array}{l}\text { CNT/Ionic } \\
\text { liquidGCE }\end{array}$ & - & $5-900$ & - & 2 & [32] \\
\hline Graphene/GCE & $4-100$ & - & 2.64 & - & [33] \\
\hline $\begin{array}{c}\text { Pt-Au } \\
\text { hybrid/GCE }\end{array}$ & $\begin{array}{l}24- \\
384\end{array}$ & $\begin{array}{l}21- \\
336\end{array}$ & 24 & 21 & [34] \\
\hline $\mathrm{rGO} / \mathrm{GCE}$ & $\begin{array}{c}0.5- \\
1000\end{array}$ & $\begin{array}{c}0.5- \\
1000\end{array}$ & 0.67 & 0.69 & $\begin{array}{l}\text { This } \\
\text { work }\end{array}$ \\
\hline
\end{tabular}


EDAX indicated the component of 0 elements in rGO films was about $57.68 \%$ elements of $\mathrm{C}$ and $\mathrm{Na}$ were also observed. The presence of oxygen-containing functional groups provided more opportunities for potential applications of rGO in many areas. These data will provide a reference to further study of graphene. Electrochemical behavior of rGO modified glassy carbon electrode investigated with reference to $\left[\mathrm{Fe}(\mathrm{CN})_{6}\right]^{3-/ 4-}$ redox system reflect that the electrochemical behavior is controlled by the electron transfer. rGO/GCE displayed desirable properties including low detection limit, excellent stability, reproducibility, selectivity and sensitivity. Therefore, rGO/GCE would act as a promising sensor for a wide range of electrochemical sensing.

\section{References}

[1] L. Liao, Y.-C. Lin, M. Bao, R. Cheng, J. Bai, Y. Liu, Y. $\mathrm{Qu}$, K.L. Wang, Y. Huang and X. Duan. Nature, 2010, 467, 305.

[2] F. Bonaccorso, Z. Sun, T. Hasan and A. Ferrari. Nature photonics, 2010, 4, 611 .

[3] H. Chang, Z. Sun, M. Saito, Q. Yuan, H. Zhang, J. Li, Z. Wang, T. Fujita, F. Ding and Z. Zheng. Acs Nano, 2013, 7, 6310-6320.

[4] M. Zhou, Y. Zhai and S. Dong. Analytical chemistry, 2009, 81, 5603-5613.

[5] A. Babaei, M. Aminikhah and A.R. Taheri. Sensor letters, 2013, 11, 413-422.

[6] A. Rochefort and J.D. Wuest. Langmuir, 2008, 25, 210215.

[7] A. Krishnan, E. Dujardin, M. Treacy, J. Hugdahl, S. Lynum and T. Ebbesen. Nature, 1997, 388, 451.

[8] T. Land, T. Michely, R. Behm, J. Hemminger and G. Comsa. Surface Science, 1992, 264, 261-270.

[9] A. Nagashima, K. Nuka, H. Itoh, T. Ichinokawa, C. Oshima and S. Otani. Surface Science, 1993, 291, 93-98.

[10] S. Stankovich, D.A. Dikin, G.H. Dommett, K.M. Kohlhaas, E.J. Zimney, E.A. Stach, R.D. Piner, S.T. Nguyen and R.S. Ruoff. nature, 2006, 442, 282.

[11] C. Gómez-Navarro, R.T. Weitz, A.M. Bittner, M. Scolari, A. Mews, M. Burghard and K. Kern. Nano letters, 2007, 7, 3499-3503.

[12] Y. Xu, H. Bai, G. Lu, C. Li and G. Shi. Journal of the American Chemical Society, 2008, 130, 5856-5857.
[13] H.A. Becerril, J. Mao, Z. Liu, R.M. Stoltenberg, Z. Bao and Y. Chen. ACS nano, 2008, 2, 463-470.

[14] S. Stankovich, D.A. Dikin, R.D. Piner, K.A. Kohlhaas, A. Kleinhammes, Y. Jia, Y. Wu, S.T. Nguyen and R.S. Ruoff. carbon, 2007, 45, 1558-1565.

[15] S. Park and R.S. Ruoff. Nature nanotechnology, 2009, 4, 217.

[16] W.S. Hummers Jr and R.E. Offeman. Journal of the american chemical society, 1958, 80, 1339-1339.

[17] A. babaei and A. Taheri. Anal. Bioanal. Electrochem., 2012, 4, 342 - 356.

[18] R. Cui, X. Wang, G. Zhang and C. Wang. Sensors and Actuators B: Chemical, 2012, 161, 1139-1143.

[19] G. Fabregat, F. Estrany, M.T. Casas, C. Alemán and E . Armelin. The Journal of Physical Chemistry B, 2014, 118, 4702-4709.

[20] J. Huang, Y. Liu, H. Hou and T. You. Biosensors and Bioelectronics, 2008, 24, 632-637.

[21] F. Ni, Y. Wang, D. Zhang, F. Gao and M. Li. Electroanalysis: An International Journal Devoted to Fundamental and Practical Aspects of Electroanalysis, 2010, 22, 1130-1135.

[22] K. Kamari and A. Taheri. Journal of the Taiwan Institute of Chemical Engineers, 2018, 86, 230-239.

[23] T. Kuila, S. Bose, A.K. Mishra, P. Khanra, N.H. Kim and J.H. Lee. Progress in Materials Science, 2012, 57, 1061-1105.

[24] A.K. Mishra and S. Ramaprabhu. Desalination, 2011, 282, 39-45.

[25] H.J. Shin, K.K. Kim, A. Benayad, S.M. Yoon, H.K. Park, I.S. Jung, M.H. Jin, H.K. Jeong, J.M. Kim and J.Y. Choi. Advanced Functional Materials, 2009, 19, 1987-1992.

[26] R. Ramachandran, S. Felix, G.M. Joshi, B.P. Raghupathy, S.K. Jeong and A.N. Grace. Materials Research Bulletin, 2013, 48, 3834-3842.

[27] K. Krishnamoorthy, M. Veerapandian, L.-H. Zhang, K. Yun and S.J. Kim. The journal of physical chemistry C, 2012, 116, 17280-17287.

[28] J. Paredes, S. Villar-Rodil, A. Martínez-Alonso and J. Tascon. Langmuir, 2008, 24, 10560-10564.

[29] S. Saxena, T.A. Tyson, S. Shukla, E. Negusse, H. Chen and J. Bai. Applied Physics Letters, 2011, 99, 013104.

[30] Y. Wang, Y. Li, L. Tang, J. Lu and J. Li. Electrochemistry Communications, 2009, 11, 889. 892.

[31] S. Trusso, B. Fazio, E. Fazio, F. Neri and F. Barreca. Thin Solid Films, 2010, 518, 5409-5415.

[32] M. Mazloum-Ardakani and A. Khoshroo. Journal of Electroanalytical Chemistry, 2014, 717, 17-23.

[33] Y.-R. Kim, S. Bong, Y.-J. Kang, Y. Yang, R.K. Mahajan, J.S. Kim and H. Kim. Biosensors and Bioelectronics, 2010, 25, 2366-2369. 
[34] S. Thiagarajan and S.-M. Chen. Talanta, 2007, 74, $212-$ 222. 